\title{
Cellular Aging: Theories and Technological Influence
}

\author{
Silvia Mercado-Sáenz, Miguel J. Ruiz-Gómez*, Francisco Morales-Moreno and Manuel \\ Martínez-Morillo \\ Laboratory of Radiobiology; Department of Radiology and Physical Medicine; Faculty of Medicine; University of \\ Malaga; Teatinos s/n; 29071 - Malaga - Spain
}

\begin{abstract}
The aim of this article was to review the factors that influence the aging, relationship of aging with the biological rhythms and new technologies as well as the main theories to explain the aging, and to analysis the causes of aging. The theories to explain the aging could be put into two groups: those based on a program that controlled the regression of the organism and those that postulated that the deterioration was due to mutations. It was concluded that aging was a multifactorial process. Genetic factors indicated the maximum longevity of the individual and environmental factors responsible for the real longevity of the individual. It would be necessary to guarantee from early age the conservation of a natural life rhythm.
\end{abstract}

Key words: Aging; longevity; biological rhythms; caloric restriction; telomerase; free radical

\section{INTRODUCTION}

Aging is the process of becoming older. This traditional definition was recently challenged in the new encyclopedia of Gerontology (Birren, 2006), where aging was specifically defined as the process of a system's deterioration through time. Another definition of aging is the progressive loss of physiological functions that increases the probability of death (Gómez Rinessi et al., 2000). The definitions of aging differ between the biologists and behavioral scientists. Biologists regard aging as reflecting the sum of multiple and typical biological decrements occurring after the sexual maturity; nevertheless behavioral scientists view it as reflecting regular and expected changes occurring in genetically representative organisms advancing through the life cycle under normal environmental conditions (McGue et al., 1993).
Several theories have been proposed to explain the nature of aging. Due to the multicasual nature of this process, it turns out improbable that only one theory could explain all its mechanisms. It is necessary to bear two important points in mind: (1) the process of aging compromises a number of different genes, and (2) there are multiple mutations that concern all the processes of aging. The process of aging happens to all the levels: from the molecular level, to the cellular and organ level.

One difficulty in defining the normal aging is that many changes observed in older adults and previously perceived as concomitants of normal aging are now recognized as the effects of disease in later life, as for example the Alzheimer disease (Salgado and Guillén, 1998; Gutierrez, 1998).

One must differentiate between life span and life expectancy. Life expectancy is the average number of years of life in a given species and life span is

*Author for correspondence: mjrg@uma.es 
the maximum number of years of life possible for that species, which is more fundamentally linked to the process of aging itself. (Texidor and Massó, 1997). Over a period of time, the life expectancy for human beings has increased (due to improved food, sanitation and health care practices), nevertheless the life span has not. Approximately 120 years appears to be the upper limit of life span in humans (Gómez Rinessi et al., 2000). Table 1 shows the percentages of population over 65 years old in the years 2000 and 2050 all over the world. It is expected, in all the regions, that these percentages will increase during this period which must be considered adequately in relation to social costs and services (Diczfalusy, 1997).

Table 1 - Percentages of population over 65 years old in the years 2000 and 2050.

\begin{tabular}{|c|c|c|c|c|c|c|c|}
\hline & Europe & $\begin{array}{c}\text { North } \\
\text { America }\end{array}$ & Oceania & Asia & $\begin{array}{c}\text { Latin America } \\
\text { and the } \\
\text { Caribbean }\end{array}$ & $\begin{array}{c}\text { Middle East } \\
\text { and Northern } \\
\text { Africa }\end{array}$ & $\begin{array}{c}\text { Sub- } \\
\text { Saharian } \\
\text { Africa }\end{array}$ \\
\hline $\begin{array}{l}\text { \% populations }> \\
65 \text { years old. } \\
\text { Year } 2000\end{array}$ & 15 & 14 & 12 & 8 & 7.5 & 7.5 & 4 \\
\hline $\begin{array}{l}\% \text { populations }> \\
65 \text { years old. } \\
\text { Year } 2050\end{array}$ & 28 & 21 & 20 & 19 & 19.5 & 16 & 7.5 \\
\hline
\end{tabular}

Source: Diczfalusy, 1997.

The general phenotype of aging is characteristic of each species. Nevertheless, to analyze this process, it is necessary to begin with relatively simple animal models (Ackermann, 2003). Since the cellular mechanisms involved in response to the cytotoxic agents are conserved among the yeast and mammalian cells, the budding yeast Saccharomyces cerevisiae has become an excellent eukaryotic model for the study of basic cellular functions and identification of the molecular and cellular mechanisms of response to the agents responsible for the cellular damage (Ruiz-Gómez and MartínezMorillo, 2006). Bacteria have been also used as a model system for investigating why and how organisms age (Ackermann, 2008). The simple organisms are specially indicated in the studies about aging as their brief life cycle with short growth and aging time allow saving time and resources (Ackermann, 2003).

\section{FACTORS THAT INFLUENCE THE AGING}

The studies conducted up to the present time, have shown that $35 \%$ of the responsibility for the longevity reached by an individual is of genetic origin while $65 \%$ of it is due to the environmental factors (way of life, habits, stress, etc.) (McGue et al., 1993). The aim of the present work was to enumerate and elaborate the most important theories of aging separating them into two large groups, according to their components being genetic or environmental (Bengtson and Schaie, 1998).

\section{Genetic components of aging}

Every cell possesses a complex system for the reproduction and building of the molecules that allow it to develop. The information and the machinery to achieve it are codified in the nucleic acids (DNA and RNA) and in the proteins. In the cells the nucleic acids share an environment that contains numerous inorganic molecules, water and a great variety of reactive molecular species that can exist as excited molecules, ions or free radicals, and are later turned into chemically stable products (Bengtson and Schaie, 1998).

\section{Environmental components of aging}

Environmental damages that exceed the maintenance system of repair of the DNA can lead to premature aging. For example, prolonged exhibition to the sun will lead to a premature aging of the skin due to the high levels of ultraviolet radiation that damages the DNA (Alegre Bayo, 2001; Alcaraz et al., 2003). Humans live exposed to a diversity of magnetic fields, some of them generated by the magnetism of the earth, whereas others are generated by the solar storms and solar changes through time (Vizcaino, 2003). Electrical devices also create magnetic fields: engines, television sets, office furniture, computers, microwave ovens, electrical wires in the buildings 
and the power network that provides them. Even the human body produces subtle magnetic fields that are generated by the chemical reactions inside the cells and the ionic currents in the nervous system (Vizcaino, 2003; Cebrián Martín, 2004).

The response of a biological system to an external magnetic field depends so much on the system's magnetic properties as on the characteristics of the external field and the way in which the phenomenon takes place. The extremely low frequency nonionizing radiations, as the magnetic fields of 50 Hertz, affect a great amount of biochemical processes, such as the synthesis of nucleic acids (DNA and RNA) responsible for the genetic inheritance and production of proteins; hormone production; immune response, and cell growth and differentiation, and conditioning the appearance of cancer (Becerra Mayor and Aguilar Arjona, 2001).

The adverse effects of the electromagnetic fields include increase in the production of free radicals, both oxygen and nitrogen reactive species (ROS and RNS), decrease in the antioxidative defenses, and the stabilization and lengthening of the life span of free radicals. In addition, the total antioxidative capacity of the plasma diminishes significantly in the group of exposed people. Relating to the induction of cancer, the electromagnetic fields are not ionizing and, therefore, could affect to the processes of cell proliferation by the generation of free radicals, which in turn can act on the processes of development of cancer cells (Salido and Fernández, 2002).

Free radicals are highly reactive molecules that take part in large amount of pathological processes. Its role in aging, in the physiopathology of numerous degenerative processes, in the side effects associated with the above mentioned processes, as well as its utility in the prognosis of diverse diseases, is something that every day finds a major experimental and clinical support. Accordingly, to anticipate the production in excess of free radicals must be taken into consideration as of maximum interest to attain a healthy aging and a better prevention of the diseases associated with them (Salido and Fernández, 2002). That is why although the organism is adapted to the electromagnetic natural fields, its exposure to artificial fields can have great physiopathological importance. Mainly during the sleep time, when the cellular repair systems are at work, the elimination of these electromagnetic artificial fields has important health consequences. The aim of this work was to demonstrate how the reduction of these fields by means of rest in a controlled environment, reduces significantly the free radicals and balances the endocrine neuroinmunologic system, resulting in a better health state (Cebrián Martín, 2004).

\section{SOME THEORIES ABOUT THE AGING PROCESS}

Following is the summary of the theories proposed to explain the aging into two large groups (Toussaint, 1993):

- Those based on the existence of a program that regulates and controls the regression of the organism.

- Those that postulate that the deterioration produced by the passage of time is consequence of mistakes due to mutations that upset the function or the structure of the cells, fabrics and organs.

Possibly there are a series of processes of different category and importance involved in the aging. The genome seems to be an essential element in the determination of the total life span, while other factors like the mechanism for obtaining and liberating energy and the formation of the Reactive Oxygen Species (ROS), as well as the processes linked to the environment (radiation, changes in nutrition etc) have to be taken as part of the explanation of the regressive process (Paredes Salido and Roca Fernández, 2002).

Characteristics of aging (Wiley, 2007)

- Universal: It affects to all the living beings.

- Irreversible: Unlike the diseases, it can neither stop nor be reverted.

- Heterogeneous and individual: Every species has a typical speed of aging but the functional decline speed changes widely from subject to subject within the same species, and from organ to organ within the same individual.

- Detrimental: It leads to a progressive loss of function. It differs from the process of growth and development in which the purpose is to reach a maturity in the function.

- Intrinsic: Not due to environmental modifiable factors.

These are several theories that try to explain the process of aging (Table 2). 
Table 2 - Theories about the aging process.

Theory "Wear and Tear" Theory
The Neuroendocrine Theory
The Genetic Control Theory
Waste Accumulation Theory
Limited Number of Cell
Divisions Theory
Hayflick Limit Theory
Death Hormone Theory (DECO)

Thymic-Stimulating Theory

Mitochondrial Theory

Errors and Repairs Theory

Redundant DNA Theory

Cross-Linkage Theory

Autoimmune Theory

Caloric Restriction Theory

The Rate of Living Theory

Gene Mutation Theory

Accumulated mutations Theory

Antagonistic pleiotropy Theory

Disposable soma Theory

Order to Disorder Theory

The Telomerase Theory

Body and its cells were damaged by overuse and abuse (Warner et al., 1987)

Based on the wear and tear theory by focusing on the neuroendocrine system (Gavrilov and Gavrilova, 2006)

Genetic inheritance says about how quickly we age and how long we live (Bengtson and Schaie, 1998)

The excess waste can interfere with normal cell function, ultimately killing the cell (Gavrilov and Gavrilova, 2006)

The number of cell divisions is directly affected by the accumulations of the cell's waste products (Bengtson and Schaie, 1998)

Human cells have a limited life span (Hayflick and Moorehead, 1980)

We age because the pituitary begins to liberate DECO that increases the metabolic rate by accelerating the aging process (Bengtson and Schaie, 1998)

The disappearance of the thymus contributes to the aging process by weakening the body's immune system (Goldberg et al., 2007)

Mitochondria are one of the easiest targets of free-radical injury (Wiley, 2007)

The system is incapable of making all repairs. The accumulation of the flawed molecules causes diseases and other age changes (Warner et al., 1987)

It blames errors accumulating in genes for age changes (Bengtson and Schaie, 1998)

Old immune systems are incapable to clear excess glucose in the blood. Glucose causes cross-links and free radicals (Warner et al., 1987)

With age the system's ability to produce antibodies declines, as does its ability to distinguish between antibodies and proteins (Bengtson and Schaie, 1998)

A diet low in calories but high in nutrients, minerals and vitamins is able to delay aging (Turner, 2003)

We born with a limited amount of energy. If we use this energy slowly then our rate of aging is slowed. If the energy is consumed quickly aging is hastened (Bengtson and Schaie, 1998)

Mutations accelerate the aging process (Warner et al., 1987)

The influence of natural selection diminishes with age (Sozou and Seymour, 2004)

Natural selection has favoured genes conferring short-term benefits to the organism at the cost of deterioration in later life (Sozou and Seymour, 2004)

Cell maintenance is costly. Using extra energy to increase reproductive capacity will be more beneficial (Sozou and Seymour, 2004)

After sexual maturation the system that mantains the order starts to diminish en efficiency. Disorders are cause of aging (Bengtson and Schaie, 1998)

Every time our cells divide, telomeres are shortened, leading to cellular damage and cellular death associated with aging (Bryan et al., 1998)

Enhancement of the antioxidative defence system to attenuate free-radical-induced

The free radical Theory damage will counteract the aging process (Yokozawa et al., 2004) 


\section{The "Wear and Tear" Theory}

Dr. August Weismann, a German biologist, first introduced this theory in 1882 . He believed that the body and its cells were damaged by overuse and abuse. The organs and skin are worn down by toxins in the diet and in the environment. Wear and the tear are not confined to the organs; it also takes place at the cellular level (Warner et al., 1987).

\section{The Neuroendocrine Theory}

This theory developed by Dr. Vladimir Dilman elaborates on the wear and tear theory by focusing on the neuroendocrine system. When young, the hormones work together to regulate many bodily functions, including the responses to heat and cold, life experiences and sexual activity. Different organs release various hormones all under the governance of the hypothalamus. The hypothalamus responds to the body's hormone levels as its guide to regulating hormonal activity.

When young, hormone levels tend to be high. With the increase in the age, the body produces lower levels of hormones which can have disastrous effects on the functioning. The growth hormones, for example, drop dramatically as the age increases so that even if an elderly person has not gained weight, he or she has undoubtedly increased the ratio of fat-to-muscle.

Hormones are vital for repairing and regulating the bodily functions, and when aging causes a drop in the hormone production, it causes a decline in body's ability to repair and regulate itself as well. Thus, hormone replacement therapy, a frequent component of any anti-aging treatment, helps to reset the body's hormonal clock and so can reverse or delay the effects of aging and thus keeping young (Gavrilov and Gavrilova, 2006).

\section{The Genetic Control Theory}

This theory states that humans are born with a unique genetic code, a predetermined tendency to certain types of physical and mental functioning, and that the genetic inheritance has a great deal to say about how quickly one becomes aged and how long lives. Each person has a biological clock. When that clock goes off, it signals the bodies first to age and then to die. However, the timing on this genetic clock is subject to enormous variation, depending on what happens with the growth and on how one actually lives (quality of life, feeding, sanitation, health care practices, etc) (Bengtson and Schaie, 1998).

\section{Waste Accumulation Theory}

In the course of life span the cells produce more waste than they can properly eliminate. This waste can include various toxins which when accumulated to a certain level, can interfere with normal cell function, ultimately killing the cell. Evidence supporting this theory is the presence of a waste product called lipofuscin leading to age pigment. Lipofuscin is formed by a complex reaction that binds fat in the cells to proteins. This waste accumulates in the cells as small granules and increases in size as a person ages (Gavrilov and Gavrilova, 2006).

\section{Limited Number of Cell Divisions Theory}

The number of cell divisions is directly affected by the accumulations of the cell's waste products. The more wastes accumulates over the time, the faster cells degenerate (Bengtson and Schaie, 1998).

\section{Hayflick Limit Theory}

In 1962, two cell biologists, Dr. Hayflick and Dr. Moorehead, made one of the greatest contributions to the history of cellular biology by demonstrating the senescence of cultured human cells. Hayflick theorized that the aging process was controlled by a biological clock contained within each living cell. The 1961 studies concluded that human cells have a limited life span. The most evident changes took place in the cell organelles, membranes and genetic material. This improper functioning of cells and loss of cells in organs and tissues may be responsible for the effects of aging (Hayflick and Moorehead, 1980).

\section{Death Hormone Theory (DECO)}

Unlike other cells, brain cells or neurons do not replicate. The humans are born with roughly 12 billion of them and over a life time, about 10 percent perish. Dr. Denckle speculated that as the age increased the pituitary released DECO (decreasing oxygen consumption hormone or "death hormone"). This inhibits the ability of cells to use the thyroxine, the rate at which cells convert the food to energy. The metabolic rate increases and accelerates the process of aging (Bengtson and Schaie, 1998).

\section{Thymic-Stimulating Theory}

This theory suggests that the disappearance of the thymus contributes to the aging process by 
weakening the body's immune system. Thymic

hormones may also play a role in stimulating and controlling the production of neurotransmitters and brain and endocrine system hormones which means they may be the key regulators responsible for immunity. The size of this gland reduces from 200 to 250 grams at birth and then shrinks to around three grams by age 60 . Thymic factors are helpful in restoring the immune systems of children born without them as well as rejuvenating the poorly functioning immune systems of the elderly (Goldberg et al., 2007).

\section{Mitochondrial Theory}

The free radical theory is supported by the directed experimental observations of mitochondrial aging. They produce cell energy by a process that leads to the formation of potentially damaging free radicals. Mitochondria are also one of the easiest targets of free-radical injury because they lack most of the defenses found in other parts of the cell (Boffoli et al., 1994; Birren, 2006; Wiley, 2007).

\section{Errors and Repairs Theory}

In 1963, Dr. Leslie Orgel suggested that "an error in the machinery for making protein could be catastrophic." The production of proteins and the reproduction of DNA sometimes are not carried out with accuracy. The body's DNA is so vital that the natural repair processes kick in when an error is made. But the system is incapable of making perfect repairs on these molecules every time, and the accumulation of these flawed molecules can cause diseases and other age changes to occur (Warner et al., 1987).

\section{Redundant DNA Theory}

This theory blames errors accumulating in the genes for age changes. But, as these errors accumulate, this theory also blames the reserve genetic sequences of identical DNA that take over until the system is worn out. Dr. Zhores Medvedev proposed that different species life spans could be a function of the degree of these repeated gene sequences (Bengtson and Schaie, 1998).

\section{Cross-Linkage Theory}

Developmental aging and cross-linking were first proposed in 1942 by Johan Bjorksten. He applied this theory to aging diseases such as sclerosis, a declining immune system and the loss of elasticity in the skin. Collagen is one of the most common proteins found in the skin, tendons, ligaments, bone and cartilage. Collagen protein can be compared to the legs of a ladder with very few rungs. Each protein is connected to its neighbors by other rungs forming a cross-link (Warner et al., 1987). In young people, there are few cross-links and the ladders are free to move up and down. The collagen stays soft and pliable. It is thought that these cross-links begin to obstruct the passage of nutrients and waste between cells. Cross-linking also appears to occur when older immune systems are incapable of cleaning out excess glucose molecules in the blood. These sugar molecules react with proteins causing cross-links and the formation of destructive free radicals (Warner et al., 1987).

\section{Autoimmune Theory}

With age the system's ability to produce necessary antibodies that fight disease declines, as does its ability to distinguish between the antibodies and proteins. In a sense, the immune system becomes self-destructive and reacts against itself. Examples of autoimmune disease are lupus, scleroderma and adult-onset diabetes (Bengtson and Schaie, 1998).

\section{Caloric Restriction Theory}

Calorie restriction or energy restriction is a theory proposed by Dr. Roy Walford. He developed a high nutrient low-calorie diet demonstrating that "under nutrition with malnutrition" could dramatically retard the functional, if not the chronological aging process. An individual on this program would lose weight gradually until a point of metabolic efficiency was reached for maximum health and life span. Walford stressed the importance of not only the high-low diet but also moderate vitamin and mineral supplements coupled with regular exercise (Turner, 2003).

A major neuroendocrinological effect of calorie restriction is induction of neuropeptide $\mathrm{Y}$ in the arcuate nucleus. Aside from its appetite-stimulating effects, neuropeptide $\mathrm{Y}$ is thought to be involved in the modulation of behavioral processes including anxiety and learning and memory. Despite established effects of calorie restriction on arcuate nucleus signaling, studies suggest a mechanistic separation between the two where behavior is concerned (Minor et al., 2008).

\section{The Rate of Living Theory}

German physiologist Dr. Max Rubner who discovered the relationship among the metabolic rate, body size and longevity first introduced this 
theory in 1908. It simply states that each one is born with a limited amount of energy. If this energy is used slowly, then the rate of aging is slowed. If the energy is consumed quickly, aging is hastened. Other rate-of-living theories focus on limiting factors such as amount of oxygen inhaled or number of heartbeats spent (Bengtson and Schaie, 1998).

\section{Gene Mutation Theory}

In the 1940s, the scientists investigated the role of mutations in aging. Mutations are changes that occur in the genes which are fundamental to life. Evidence supporting this idea came from the experiments with radiation. It was observed that radiation not only increased animal's gene mutation but it also accelerated their aging process as well. However, later studies showed the radiation-induced changes were only mimicking age changes. This hypothesis further diminished in validity when the experiments with moderate amounts of radiation actually increased the life span of rats (Warner et al., 1987).

\section{Accumulated mutations theory}

It was first proposed by Medawar in 1952. This theory suggests that influence of natural selection diminishes with age. When there is a deleterious mutation that manifests itself at a young age, there will be strong selection pressure to eliminate that mutation because it will impact the fitness of a large majority of the population. If that same mutation does not manifest itself until late in life, many of the individuals carrying the mutation will be dead before the mutation is expressed. If the mutation is rarely expressed, can be passed from one generation to the next and may accumulate in the genome, because there is little opportunity for natural selection to clear this mutation from the genome (Sozou and Seymour, 2004).

\section{Antagonistic pleiotropy theory}

Antagonistic pleiotropy is the second evolutionary theory of aging. It was formulated by Williams in 1957 and proposed that genes existed which have beneficial effects early in life but harmful effects later in life. If these genes confer increased reproductive success early in life, they would be selected for despite the fact that they may later cause senescence (Sozou and Seymour, 2004).

\section{Disposable soma theory}

Cell maintenance is costly. Given the fact that extrinsic mortality is extremely high in the wild, it would make little sense to use precious metabolic resources to maintain the soma beyond the expected lifetime of the organism. Using extra energy to increase the reproductive capacity will be more beneficial from an evolutionary standpoint because it will enhance the fitness of that individual. Therefore, organisms have evolved in such a way that the amount of energy invested in maintaining the soma is sufficient to keep the animal alive long enough to reproduce but less than that which would be required to keep it alive indefinitely.

The disposable soma theory helps to explain why different species have different life spans. The higher the extrinsic mortality rate for a species, the more energy should be directed towards reproducing as often as is possible (Sozou and Seymour, 2004).

\section{Order to Disorder Theory}

From the time of conception to sexual maturation, human bodies undergo a system of orderliness. Dr. Leonard Hayflick mentioned that humans direct most of the energies to fulfilling a genetically determined plan for the orderly production and arrangement of an enormous number and variety of molecules. After the sexual maturation, however, these energies start to diminish its efficiency. Disorder occurs in the molecules in turn causing other molecules to produce errors and so on. These chaotic changes in the cells, tissues and organs are the causes of aging. Disorderliness varies from individual and this may be the reason why the tissues and organs deteriorate at different rates (Bengtson and Schaie, 1998).

\section{The Telomerase Theory of Aging}

This theory was born from the surge of technological breakthroughs in genetics and genetic engineering. Telomeres are sequences of nucleic acids extending from the ends of chromosomes. Telomeres act to maintain the integrity of the chromosomes. Every time the cells divide, telomeres are shortened, leading to cellular damage and cellular death associated with aging (Bryan et al., 1998; Goyns and Lavery, 2000).

The key element in rebuilding the disappearing telomeres is the enzyme telomerase, an enzyme found only in germ cells and cancer cells (Sedivy, 2003). Telomerase appears to repair and replace the telomeres manipulating the "clocking" mechanism that controls the life span of dividing cells (Allen, 1996; Bodnar et al., 1998; Shay and Wright, 2000).

\section{The free radical theory}


This theory suggests that the enhancement of the antioxidative defence system to attenuate freeradical-induced damage counteracts the aging process. Among the various theories of the aging process, the free radical theory, which proposes that deleterious actions of free radicals are responsible for the functional deterioration associated with aging, has received widespread attention. Some studies have indicated that the aging process leads to suppression of the antioxidative defense system and accumulation of lipid peroxidation products, while ginsenoside-Rd attenuates the oxidative damage, which may be responsible for the intervention of GSH/GSSG redox status (Yokozawa et al., 2004).

Age-related changes do not occur uniformly in the individuals; rather they are controlled jointly by the genetic and environmental factors which further heighten the difficulty of finding a universal theory. What is universal is that there exists a global-aging phenomenon. Through the theoretical gerontology and anti-aging medicine, one may eventually discover that there is no limit to human life span (González Jiménez, 2000).

\section{BIOLOGICAL RHYTHM AND AGING}

The biological rhythms reflect the adaptation of the organisms so that certain events take place at the most appropriate moment of the day or year. The physiological mechanisms used by the living organisms to this end are organized around several biological clocks determined genetically that persist in isolated state, thus demonstrating its endogenous nature.

The biological rhythms are clasified in three large groups, according to its frequency of oscillation:

- Circadian rhythms are roughly 24 cycles. These include the light-dark rhythm, whose information is transmitted through the retinohypothalamic tract. Most of the rhythms studied in chronobiology belong to this group.

- Ultradian rhythms have periods of less than 20 such as heart beating and lung ventilation.

- Infradian rhythms have periods longer than 28 such as the human menstrual cycle.

A biological variable can present rhythms of different frequency simultaneously, for example the ultradian releases of some hormones such us cortisol that at the same time present a 24 circadian rhythm (Sharma et al., 1989).

Although there are several brain structures that take part in the regulation and maintenance of the circadian rhythms, the hypothalamus CNS (Central nervous system) is considered the key structure in

this process. As the CNS is the endogenous regulator of the pineal gland, it seems that there is a feedback relation between them (Mess and Rúzsas, 1986), thus suggesting that melatonin can influence directly the CNS, and consequently, to the circadian rhythms. Several authors have reported the presence of melatonin receptor in the CNS (Vanecek et al., 1987).

The circadian system develops during the postnatal period. Newborns present an irregular pattern for the first four weeks after birth; between the 5th and 9th week, a pattern similar to a free running circadian rhythm appears and from the 16th week, it presents a sleep-wake cycle similar to that of adults. The development of the rhythms is influenced by the mother before and after birth, as well as by the environment (light and food access) (Mess and Rúzsas, 1986).

The characteristics of the circadian rhythms stay throughout the adult life. However, in old age, a series of changes occur, as a shortening of the tau protein, a lessening of the width of the circadian rhythm, the appearance of an ultradian rhythm and an inner desynchronization (Antoniadis et al., 2000). The stability of the circadian system is related to the length of the rhythms and the loss of circadian length causes unsteadiness, which creates a temporary internal disorder that can be a cause of illnesses. Some studies performed on women and men with ages between 19 and 89 found a weakened answer of the circadian system to the day-night cycle in aging, as well as an altered relation between the melatonin and cortisol markers (Sharma et al., 1989). The biological aging is often associated with the problems of the sleep-wake rhythm. Several studies have shown up the possible influence of melatonin in persons with sleep disorders. Exogenous melatonin could prevent these problems through its action over the circadian sleep signals.

One of the characteristics of aging is the loss or reduction of the effectiveness of the homeostatic mechanisms that act against external stimuli or internal imbalances in the organism. Aging implies, in addition, an alteration of the predictive homeostasis, this being understood as an anticipatory response to an expected challenging the event in the future. Nevertheless, in spite of the high incidence of alterations of the rhythms in the metabolism, nutrition, sleep-wake cycle (nocturnal fragmentation, diurnal somnolence, insomnia) and 
other circadian rhythms like the central temperature, cortisol and melatonin rhythms with age, very little

is known about how the circadian system ages, the main regulator of the predictive homeostasis (Golombek, 2002).

There is a double relationship between the circadian system and aging, as not only does the circadian system show aging symptons (shortening of length, phase advancement and rhythms inter-daily instability) but also the primary alteration of the circadian system can be a cause of aging (Golombek, 2002).

The existence of a circadian regulation is considered to be beneficial for the organism. Therefore, an abnormal pattern of life habits can be considered as an additional risk factor that contributes to the development of many diseases associated to aging, such as cardiovascular disease, diabetes and cancer, although the underlying molecular mechanisms are not clear. Traditionally, it has been suggested that temporary internal disorganization of the different rythmical variables was the cause of the problem. However, recent studies have shown that the alteration of the expression of the genes clock, Bmal1, Clock, Cry and Per genes also could be responsible for the accelerated aging caused by disruptions of life habits patterns (Antoniadis et al., 2000).

It has been proved that a constant alteration of biological rhythms accelerates the process of aging. For example, people who change shifts in their jobs for a long period in their life age more intensely due to their continuous changing of their histological rhythms and their sleep-wake cycle. Furthermore, the changes in the cortisol levels (a hormone related to stress) at its highest when awakening and diminishing until night, could accelerates the process of aging (Duncan and Marilyn, 2007).

\section{INFLUENCE OF TECHNOLOGY ON AGING}

The technology has helped to improve the quality of life and to increase the longevity of the population. Gutiérrez (1998) analyzed the positive and negative effects that technology has in the aging or in an improvement of the living conditions in the third age.

The improvements in the health and quality of life brought by the technological advances can be considered as positive effects as below:
The elderly and people with special abilities can benefit from the technology (optical, hearing aids and orthopaedic material) to improve and overcome the limitations and difficulties they face in their activities in daily life, so that these people maintain their autonomy, productivity and dignity as they age, thus contributing to an improvement of quality of life (Salgado and Guillén, 1990).

There have been major technological advances in the biomedical sciences. Technology has helped to improve the medicine in general and the production of new drugs, which have resulted in significant advances in health that have caused the increase in life expectancy and an improvement in quality. Not only one lives more years, but age later and better.

These can improved and innoved diagnostic systems (scanners, X-ray, ultrasound, gamma lettering, etc.). Laser technology has allowed the correction of visual ailments as cataracts, myopia, etc.

The laparoscopic surgery reduces the risk of postoperative infections and improves the recovery of the individual, shortens the time resting avoiding potential complications. The various prostheses increasingly have enabled improved ailments such as breakage occurred in the 3rd age with relative frequency can be resolved by surgery (Gutiérrez, 1998).

In the field of dentistry, dental implants and new materials represent a major step forward in improving the conditions of the elders. New rehabilitation techniques (thermotherapy, hydrotherapy, laser photocoagulation, electrotherapy, and cryotherapy) allow the recovery of the individual maximum functional capacity. Optical fibers are widely used in medical instruments to look inside the human body and to perform laser surgery because its can transmit high quality images (Alcantud and Sotos, 2008).

In telecommunications, remote alert and/or teleassistance systems that can be implanted into the homes of the elderly person who needs assistance to their families it also ensures a rapid intervention of health services. The same is true for mobile phones (Bettetini and Colombo, 1995). Better communications and the availability of transportation means increasingly effective guarantee the mobility of the elderly, and/or transferring them to hospitals in case of need. Advances in mechanics have enabled the persons with reduced mobility with a better quality of life, thanks to the mechanized wheelchairs (Alcantud and Sotos, 2008). 
In recent years, progress is being made in anti-aging medicine. This is a personalized study from the point of view biochemical and molecular genetic, which allows the subject from the point of view of its past and future biological, ordered by their genes, as well as its biochemical present because of their habits (Zaragoza et al., 2003). These data were looking for a better balance in order to delay and improve the aging process (Alcantud and Sotos, 2008).

The reduction of architectural barriers, widespread use of elevators, improved nutrition and food preservation, advances in microelectronics and computer technology, improvements in the quality of work due to technological support due to the machines and computers, radio, television and internet have made the life more comfortable, thus improving the quality, decreasing Wear Daily, and thus, increase the lifespan (George and Bearon, 1980).

Much of the world's population, mainly in the industrialized countries, has a better standard of living in all areas: food, health, clothing, housing, education, leisure, work at home, etc. In short, today many people have a longer life expectancy and healthier as a result of technology (Gómez-Vela and Sabeh, 2001).

It could be concluded that in the short or long term, all the technological advances result in a benefit to all the sectors of society, which translates into a better quality of life and an increase in the life expectancy.

However, despite all the benefits that undoubtedly involve technological advances over the past decades, some observers have begun to warn about some destructive and harmful aspects derived from the technology (Prutkin and Feinstein, 2002):

- Air pollution, which comes from many sources, especially from the power stations, which burn fossil fuels, nuclear disasters and the exhausts of cars, in addition to their possible participation in the "greenhouse effect" or climate change exacerbates respiratory diseases and allergies. Likewise, the reduction of the ozone layer caused by the emission leads to intensify the ultraviolet radiation with serious health hazards and consequences as photoaging and skin cancer. In addition to these, such emissions are often rich in lead, with the risk posed to health.

- The massive use of pesticides such as DDT threatens the food chain.
- The tailings are used by the industry which pollutes the rivers, lakes and seas, as well as reserves of groundwater with the serious risk.

- The waste storage causing pollutants ending up in the food webs.

- In addition to the above, noise and electromagnetic pollution (Wilkening and Sutton, 1990).

The term noise pollution, refers as a excessive and annoying sound, caused by the human activities (traffic, industry, entertainment venues, etc.), which produce negative effects on hearing health, physical and mental, causing extensive damage to the quality of life. Noise pollution can cause inter alia, the following effects: decreased hearing temporarily or permanently, the appearance of ringing in the ears (tinnitus), loss of balance, increased blood pressure, headache, difficulty sleeping, nervous tension stress, irritability and aggressiveness and other behavior disorders, difficulty concentrating, loss of efficiency, mayor probability of accident (Wilkening and Sutton, 1990). Noise pollution may increase the aging of the auditory apparatus in 20-40 years, depending on the intensity and length of exposure. There are no definitive studies linking the aging and noise pollution, but the disruption it causes (stress, sleep disturbance, behaviour, etc.) certainly influence a worse aging (Seballos Palma, 2005).

The electromagnetic pollution, is due to the development of electrical and communications. Such pollution is produced by the electric or magnetic fields, which are produced by the electric current, radio and television, mobile phone, microwave, etc (Wilkening and Sutton, 1990). Although in this field many studies have been reported, they do not show conclusive effects on the health and aging. Being subjected to continuous magnetic fields, both natural and artificial concern for electropolution is potent. World Health Organization has made efforts in order to clarify the effects of electromagnetic pollution. It is also important to highlight the work done by the Commission of the European Communities, which in 1998 made recommendations for European countries for electromagnetic pollution (Cuinas et al., 2005).

The laptop, connected to the internet via $\mathrm{Wi}-\mathrm{Fi}$, mobile phone or handheld computers allow the people to stay contacted with the work no matter where one. These resources provide flexible working hours and increase efficiency, but also blur the boundary between the work and leisure, which adversely affects the professionals and the 
reconciliation between the work and family (Conde and De la Torre y Vega, 2001). This can cause an increase in stress and heart disease, but these consequences are not the result of technology but the wrong use.

\section{SUMMARY AND CONCLUSIONS}

After a study of the different definitions and theories of aging, none of them explains the process in its entirety, since aging is considered to be a multifactorial process (Warner et al., 1987). Aging is associated with two joint processes, progressive cell degeneration and the loss of regenerative capacity. Both processes occur in each stage of life and remain in a perfect balance under normal conditions. The damaged cells are replaced and the functional integrity of fabrics and organs is preserved (Metz and Bravo, 2002). Nevertheless, in aging the balance gets lost and it inclines towards degeneracy. The mechanisms of deterioration are principally related to the generation of Reactive Oxigen Species (ROS) and to the glycosylation of proteins; both processes narrowly relate to environmental factors. On the other hand, the loss of the capacity of proliferation and regeneration is determined genetically by the shortening of the telomeres and by the processes of cellular death (Knaposwski et al., 2002; Bushell, 2005).

Both exogenous and endogenous factors can be observed in aging which support the idea that there is not a single factor causing aging but that multiple connected processes contribute to it, and it is their balance which determinates the development of aging in the individual (Warner et al., 1987).

A constant change in life habits accelerates the process of aging, thus in order to reach a healthier aging, it is necessary to keep stability in the biological cycles in youth, especially the sleep-wake cycle so that the rest may remain stable (Antoniadis et al., 2000). The environmental and genetic factors are accountable for the differences in longevity that exist between the individuals of the same species. In practice, what really matters is the functional age of the person, and not its chronological age. It is this which indicates the capacity of autonomy and quality of life. The process of aging is far away from understanding completly and even further from the possibility of reverting or lengthening it. The "eternal youth" formula is yet to be found (Fernández-Ballesteros et al., 1999).

According to the genetic factors theory, the maximum life span is determined by the longevity in every species, which in humans is 120 years. The primary aim is to achieve to equalize the life expectation with this maximum predetermined longevity, meaning that "the secret to prolong life is the art of learning how not to shorten it" (Texidor and Massó, 1997).

According to the genomic theory, the genes are responsible for the maximum span of life, though only between 25 and $35 \%$ of the longevity might be imputed to them. The rest correspond to the environmental factors, as have been demonstrated by McGue et al (1993) in the human Danish twins, and Ljunqquist et al (1998) in the identical Swedish twins. This is corroborated by the fact of the unusual increase of the life expectancy in the last century in the developed countries. Therefore, it could be concluded that the genetic factors indicate the maximum longevity of the individual and environmental factors shape it and are responsible for the real longevity of the individual (Semsei, 2000). In order to reach a healthier old age, and keep working the natural system of defense of the organism, it is necessary to guarantee from early age the conservation of a natural life rhythm, so that the sleep, wake, feeding, work and other schedules remain stable (Antoniadis et al., 2000). According to Semsei (2000) any factor that helps to support or raise the level of information operates against the aging, and any diminishing one produces the opposite effect. Aging, as any other function of the organism, is produced by the interaction of several molecular mechanisms that act simultaneously (Pardue and Baryshe, 1999). Among them the following ones are important:

- The shortening of the telomere due to the suppression of the telomerase in the first stages of the embryogenesis.

- The activation of a mechanism related to the age that stimulates the synthesis of the heat shock proteins.

- The incomplete suppression of the production and elimination of the reactive oxygen species.

- The accumulation of mutations in the genome of the somatic cells, which inexorably leads to the development of neoplasias, to the atrophy of the fabrics and to the decrease of the function of the organs (Weng et al., 1997).

In human evolution, the systems of aging develop across the following sequence: shortening of the telomere, aging of the mitochondria, accumulation of the mutations, genetic expression of aging, apoptosic atrophy of the somatic fabrics and apoptosic atrophy of the female reproductive fabrics (Bowles, 1998). It is possible that none of these by 
themselves are able to kill the organism, though they can debilitate it, but what is sure that the concurrence of them leads inexorably to death (Gómez Rinessi et al., 2000).

The analysis of these diseases of premature aging has reinforced the notion that the maintenance of the soma is critical to delay the process of aging. Faults that reduce the skill of the body in repairing efficiently or removing damaged macromolecules are accelerators of the process of aging (Bodnar et al., 1998). Thanks to technological advances human beings enjoy today more amenities, more availability of services, access to information, greater longevity and health, among other benefits, but one must not forget the negative effects. With a good awareness of the problems both by the companies as well as by the users, and making the investments and relevant studies, one can minimize the negative effects and can enjoy all the possibilities that technology puts at one's disposal (Alcantud and Sotos, 2008).

\section{ACKNOWLEDGEMENTS}

The authors wish to thank Prof. Dra. L. de la Peña for her indications and support, Ms. L. GilCarmona for her selfless cooperation, and Mr. I. García Oncala for translation of this article.

\section{REFERENCES}

Ackermann, M. (2008), Bacteria as a new model system for aging studies: investigations using light microscopy. Biotechniques, 44, 564-567.

Ackermann, M.; Stearns, S. C.; Jenal, U. (2003), Senescence in a bacterium with asymmetric division. Science, 300, 1920.

Alcantud, F.; Sotos, C. (2008), Discapacidad, envejecimiento y dependencia: el papel de las tecnologías. In-Estudios para la salud, ed. Generalitat Valenciana, Valencia, p. 22.

Alcaraz, M.; Solano, F.; Vicente, V.; Canteras, M. (2003), Effect of radiation on thyroid peroxidase activity in rabbit. Radiobiología, 3, 59-62. ISSN 1579-3087

Alegre Bayo, N. (2001), Reacción celular ante la radiación. Radiobiología, 1, 9-11. ISSN 1579-3087

Allen, J. F. (1996), Separate sexes and the mitochondrial theory of ageing. J. Theor. Biol., 180, 135-140.

Antoniadis, E. A.; Ko C. H.; Ralph, M. R.; McDonald, R. J. (2000), Circadian rhythms, aging and memory. Behav. Brain Res., 111, 25-37.
Becerra Mayor, M.; Aguilar Arjona, J. A. (2001), Radiación ultravioleta y cáncer de piel. Consejos preventivos. Radiobiología, 1, 15-17. ISSN 15793087

Bengtson, V. L.; Schaie, K. W. (1998), Handbook of Theories of Aging. Springer Publishing Company, New York.

Bettetini, G.; Colombo, F. (1995), Las nuevas tecnologías de la comunicación. Ed. Paidós, Barcelona.

Birren, J. E. (2006), Encyclopedia of Gerontology. Academic Press, London.

Bodnar, A. G.; Ouellette, M.; Frolkis, M.; Holt, S. E.; Chiu, C. P.; Morin, G. B.; Harley, C. B.; Shay, J. W.; Lichtsteiner, S.; Wright, W. E. (1998), Extension of life-span by introduction of telomerase into normal human cells. Science, 279, 349-352.

Boffoli, D.; Scacco, S. C.; Vergari, R.; Solarino, G.; Santacroce, G.; Papa, S. (1994), Decline with age of the respiratory chain activity in human skeletal muscle. Biochim. Biophys. Acta, 1226, 73-82.

Bowles, J. T. (1998), The evolution of aging: a new approach to an old problem of biology. Med. Hypotheses, 51, 179-221.

Bryan, T. M.; Englezou, A.; Dunham M. A.; Reddel, R. R. (1998), Telomere length dynamics in telomerasepositive immortal human cell populations. Exp. Cell. Res., 239, 370-378.

Bushell, W. C. (2005), From molecular biology to antiaging cognitive-behavioral practices: the pioneering research of Walter Pierpaoli on the pineal and bone marrow foreshadows the contemporary revolution in stem cell and regenerative biology. Ann. NY Acad. Sci., 1057, 28-49.

Cebrián Martín, M. G. (2004), Campos electromagnéticos: revisión de 56 artículos que estudian múltiples efectos. Radiobiología, 4, 89-93. ISSN 1579-3087

Conde, J. A.; De la Torre y Vega, M. T. (2001), Technological Change. Necesary Organizational strategy that effects workers. Psychology in Spain, 5, 75-81. ISSN 1137-9685.

Cuinas, I; Alejos, A. V.; Sanchez, M. G. (2005), Vegetal barriers for minimising electromagnetic pollution at cellular phone bands. Electronics Letters, 41, 340-341.

Diczfalusy, E. (1997), Growing rapidly and ageing rapidly, or the tyranny of numbers. First Consensus Meeting on Menopause in the East Asian Region. Ed. Ratnam, SS; Campana, A., Geneva, 26 - 30 May.

Duncan, Marilyn J. (2007), Aging of the Mammalian Circadian Timing System: Changes in the Central Pacemaker and Its Regulation by Photic and Nonphotic Signals. Neuroembryol. Aging, 4, 85-101. 
Fernández-Ballesteros, R.; Moya, R.; Iñiguez, J.; Zamarrón, M. D. (1999), Qué es Psicología de la vejez. Biblioteca Nueva, Madrid.

Gavrilov, L. A.; Gavrilova, N. S. (2006), Reliability Theory of Aging and Longevity. In-Handbook of the Biology of Aging, ed. Masoro E. J. and Austad S. N, Academic Press, San Diego, CA, pp. 3-42.

George, L. K.; Bearon, L. B. (1980), Quality of life in older persons: Meaning and measurement. Human Sciences Press, New York.

Goldberg, G. L.; Alpdogan, O.; Muriglan, S.J.; Hammett, M. V.; Milton, M. K.; Eng, J. M.; Hubbard, V. M.; Kochman, A.; Willis, L. M.; Greenberg, A. S.; Tjoe, K. H.; Sutherland, J. S.; Chidgey, A.; Van den Brink, M. R.; Boyd, R. L. (2007), Enhanced immune reconstitution by sex steroid ablation following allogeneic hemopoietic stem cell transplantation. $J$. Immunol., 178, 7473-7484.

Golombek, D. (2002), Cronobiología Humana: Ritmos y relojes biológicos en la salud y en la enfermedad. Universidad Nacional de Quilmes, Buenos Aires.

Gómez Rinessi, J. F.; Saiach, S.; Lecuna, N. (2000), Envejecimiento. Revista de Postgrado de la VIa Cátedra de Medicina, 100, 21-23

Gómez-Vela, M.; Sabeh, E. (2001), Calidad de Vida. Evolución del Concepto y su influencia en la investigación y en la práctica. Instituto Universitario de Integración en la Comunidad, Universidad de Salamanca,

Salamanca. http://www3.usal.es/ inico/investigacion/invesinico/c alidad.htm

González Jiménez, E. (2000), Elementos, 37, 17-20.

Goyns, M. H.; Lavery, W. L. (2000), Telomerase and mammalian ageing: a critical appraisal. Mech. Ageing Dev., 114, 69-77

Gutiérrez, R. L. M. (1998), El proceso de envejecimiento humano: implicaciones clínicas y asistenciales. Rev. Fac. Med. UNAM, 41, 198-206.

Hayflick, L.; Moorehead, P. S.. (1980), The cell biology of human aging. Sci. Amer., 242, 58-66.

Knaposwski, J.; Wieczorowska-Tobis, K.; Witowski, J. (2002), Pathophysiology of ageing. J. Physiol. Pharmacol., 53, 135-146.

Ljunqquist, B.; Berg, S.; Lanke, J.; McClearn, G. E.; Pedersen, N. L. (1998), The effects of genetic factors for longevity: A comparison of identical and fraternal twins in the Swedish Twin Registry. J. Gerontol. Med. Sci., 53, 441-446.

McGue, M.; Vaupel, J. W.; Holm, N.; Harvald, B. (1993), Longevity is moderately heritable in a sample of Danish twins born 1870-1880. J. Gerontol. Biol. Sci., 48, 237-244.

Mess, B.; Rúzsas, C. (1986), Relationship between suprachiasmatic nuclei and rhythmic activity of the pineal gland. In-Advanced Pineal Research, eds. R.J. Reiter, M. Karasek. John Libbey Ltd., London, pp. 149-158.
Metz, C; Bravo, M. (2002), Bases moleculares del envejecimiento. Ars Médica (Revista de estudios médicos humanisticos), $\quad \mathbf{8 ,} \quad 8$. http://escuela.med.puc.cl/publ/arsmedica/ArsMedica8 /Art03.html

Minor, R. K.; Villarreal, J.; McGraw, M.; Percival, S. S.; Ingram, D. K.; de Cabo R. (2008), Calorie restriction alters physical performance but not cognition in two models of altered neuroendocrine signaling. Behav. Brain Res., 189, 202-211.

Pardue, M. L.; De Baryshe, P. G. (1999), Telomeres and telomerase: more than the end of the line. Chromosoma, 108, 73-82.

Paredes Salido, F.; Roca Fernández, J. J. (2002), Influencia de los radicales libres en el envejecimiento celular. Bioquímica, 21, 96-100.

Prutkin, J.; Feinstein, A. (2002), Quality of life Measurement: Origin and Patogénesis. Yale Journal of Biology and Medicine, 75, 79-93.

Rodes Texidor, J.; Guardia Massó, J. (1997), Medicina Interna. Masson, Barcelona

Ruiz-Gómez, M. J.; Martínez-Morillo, M. (2006), Iron (III) chloride hexahydrate does not enhance methotrexate cytotoxicity on Saccharomyces cerevisiae. Chemotherapy, 52, 226-230.

Salgado, A.; Guillén, F. (1990), Manual de Geriatría. Salvat, Barcelona

Seballos Palma, S. (2005), Polución acústica en las salas de clase y la discapacidad auditiva en los estudiantes. Revista de ciencias de la educación: Organo del Instituto Calasanz de Ciencias de la Educación, 203, 423-432. ISSN 0210-9581.

Sedivy, J. M. (2003), Reproductive cloning conserves cellular senescence. Nature Cell Biol., 5, 495-496.

Semsei, I. (2000), On the nature of aging. Mech. Ageing Dev., 117, 93-108.

Sharma, M.; Palacios-Bois, J.; Schwartz, G.; Iskandar, H.; Thakur, M.; Quirion, R.; Nair, N. P. (1989), Circadian rhythms of melatonin and cortisol in aging. Biol. Psychiatry, 25, 305-319.

Shay, J. W.; Wright, W. E. (2000), Hayflick, his limit, and cellular ageing. Nat. Rev. Mol. Cell. Biol., 1, 7276.

Sozou, P. D.; Seymour, R. M. (2004), To age or not to age. Proc. R. Soc. Lond. B. Biol. Sci., 271, 457-463.

Toussaint, O. (1993), La biología del envejecimiento celular II. El umbral crítico de acumulación de errores: sus cualidades, limitaciones y consecuencias en las enfermedades crónicas asociadas al envejecimiento. Revista de Gerontología, 3, 217-227.

Turner, R. (2003), Molecular physiology: Tuned for longer life. Nature, 423, 125.

Vanecek, J.; Paulik, A.; Illnerova, H. (1987), Hypothalamic melatonin receptor sites revealed by autoradiography. Brain Res., 435, 359-362.

Vizcaino, V. (2003), Biological effects of low frequency electromagnetic fields. Radiobiología, 3, 44-46. ISSN 1579-3087 
Warner, H. R.; Butler, R. N.; Richard, L.; Sprott, P.D. (1987), Modern Biological Theories of Aging. Raven Press, New York.

Weng, N. P.; Palmer, L. D.; Levine, B. L.; Lane, H. C.; June, C. H.; Hodes, R. J. (1997), Tales of tails: regulation of telomere length and telomerase activity during lymphocyte development, differentiation, activation, and aging. Immunol Rev., 160, 43-54.

Wiley, J. (2007), Encyclopedia of Life Sciences. John Wiley and Sons Inc., Oxford

Wilkening, G.; Sutton, C. (1990), Health Effects of Nonionizing Radiation. Med. Clin. North Am., 74, 489-507.

Yokozawa, T.; Satoh, A.; Cho, E. J. (2004), Ginsenoside-Rd attenuates oxidative damage related to aging in senescence-accelerated mice. J. Pharm. Pharmacol., 56, 107-113.

Zaragoza, J. R.; Zaragoza, J.; Márquez-Serres, J. (2003), Medicina Antienvejecimiento. Historia y Teoría. In-Approaches to Aging Control. Revista de la Sociedad Española de Medicina Antienvejecimiento y Longevidad y de la Federación Iberolatinoamericana de Sociedades de Medicina Antienvejecimiento, Sevilla, p. 1.

Received: May 06, 2008; Revised: July 15, 2009; Accepted: May 13, 2010. 